\title{
Effect of dietary alpine butter rich in conjugated linoleic acid on milk fat composition of lactating sows
}

\author{
Alexandra Schmid*, Marius Collomb, Giuseppe Bee, Ulrich Bütikofer, Daniel Wechsler, Pius Eberhard \\ and Robert Sieber \\ Agroscope Liebefeld-Posieux Research Station ALP, Schwarzenburgstrasse 161, CH-3003 Bern, Switzerland \\ (Received 14 March 2007 - Revised 18 September 2007 - Accepted 26 October 2007 - First published online 18 February 2008)
}

Multiparous sows ( $n$ 17) were included in a controlled cross-over-study in order to investigate the influence of a natural source of conjugated linoleic acid (CLA) (alpine butter) on the milk fatty acid composition of lactating sows (as an animal model for lactating women) and on the growth performance of their progeny. The usual fat source of a standard lactation diet was replaced by either CLA-rich alpine butter or margarine (control diet). Compared with the margarine diet, feeding the alpine butter-supplemented diet increased $(P<0 \cdot 001)$ the CLA concentration in the milk fat (742.3 (SD 272.0) v. 107.7 (SD 34.7) $\mathrm{mg} / 100 \mathrm{~g}$ fat). Eleven of fourteen CLA isomers were higher ( $P \leq 0.004)$ in milk fat after feeding the alpine butter-supplemented diet but the transfer was not proportional. The milk fat concentration of the sow milk and the level of SFA, MUFA and PUFA were not $(P>0.05)$ affected. Growth performance of the progeny was similar for both dietary treatments. In summary, the findings show that adding alpine butter to the diet does not provoke a milk fat depression and does not alter the composition of total SFA, MUFA and PUFA in sow milk but increases its CLA concentration.

Conjugated linoleic acid: Milk: Sows: Lipids: Alpine butter

Conjugated linoleic acid (CLA) constitutes a mixture of positional and geometrical isomers of linoleic acid (cis-9,cis-12$18: 2$ ) and is naturally found in ruminant milk and meat. CLA has been demonstrated to have various beneficial health effects in animal models such as anti-adipogenic, anticarcinogenic, anti-atherogenic, antidiabetic, and immuneenhancing effects ${ }^{(1)}$. However, for humans the data are not yet conclusive. The various CLA isomers have been shown to have different physiological effects ${ }^{(2)}$. The two major isomers with known physiological activities are cis-9,trans-11$18: 2$ and trans-10,cis-12-18:2. In rats enhanced pup weight gain was determined when dams were fed a diet supplemented with CLA during the lactation period ${ }^{(3)}$. Similarly, in sows a diet supplemented with synthetic CLA during gestation and lactation markedly altered the fatty acid composition of the colostrum and mature milk and higher body weight at weaning was found in piglets weaned from sows fed the CLA-supplemented diet ${ }^{(4,5)}$.

Diets rich in high-fat dairy products increased cis-9,trans-11$18: 2$ and total lipid concentrations of human milk ${ }^{(6,7)}$. By contrast, supplementing the maternal diet with commercially synthesised CLA, which contains in addition to cis-9,trans-1118:2 also a substantial amount of trans-10,cis-12-18:2, resulted in a marked increase of the concentration of both isomers whereas the milk fat concentration was lowered compared with the control diet ${ }^{(8)}$. When maternal diets were supplemented with cheese containing a high CLA concentration (about $360 \mathrm{mg}$
CLA/100g cheese) levels of cis-9,trans-11-18:2 were increased but the fat concentration of the breast milk was not altered compared with the diet supplemented with cheese containing low CLA levels ${ }^{(9)}$.

Results from animal studies suggest that cis-9,trans-11-18:2 may be active in enhancing body-weight gain of the offspring whereas trans-10,cis-12-18:2 is responsible for depression of milk fat ${ }^{(2,9)}$. This indicates that naturally CLA-rich dairy products (high cis-9,trans-11-18:2 and low trans-10,cis-12-18:2 concentrations) may be a better option for supplementing the maternal diet than synthetic CLA supplements.

Total CLA and isomer concentrations in dairy milk depend on age, breed and the diet composition ${ }^{(10,11)}$. Pasture feeding was shown to result in higher total CLA concentrations than concentrate feeding ${ }^{(12)}$ and significantly higher cis-9,trans-11-, trans11,cis-13-, trans-8,cis-10-18:2 and total CLA concentrations were found in milk of highland cows than in their lowland counterparts $^{(13,14)}$. Alpine butter is a food naturally rich in CLA that can easily be employed in the human diet. A recent randomised, controlled, cross-over study investigated CLA and fatty acid concentrations in human milk from mothers consuming CLA-rich alpine butter or margarine in addition to their normal diet ${ }^{(15)}$. Although total CLA concentration was significantly increased in the milk of mothers offered the alpine butter, large variations were observed in regard to individual CLA isomers and among mothers. Furthermore, only five of fourteen CLA isomers were significantly increased and some 
mothers had decreasing values of certain CLA isomers when given the CLA-rich alpine butter. Whether these variations were due to the lack of compliance as suggested or are due to naturally occurring between-subject differences is difficult to determine. Sows, being single-stomached animals with strong dietary and digestive similarities to humans ${ }^{(16)}$, may be perfect as a model to verify the findings of the aforementioned human trial. Thus, the objective of the present study was to investigate the transfer of various CLA isomers from a natural dietary CLA source (alpine butter) into the milk of lactating sows and the influence on milk fatty acid composition and milk fat content. Our hypothesis was that a supplementation of the sow diet with CLA-rich alpine butter will increase the concentrations of the CLA isomers in the sow milk compared with a control diet without CLA. Furthermore, the findings were to be compared with the results of the previous human study.

\section{Experimental methods}

\section{Experimental diets, animals, and study design}

One basal lactation diet was formulated according to the Swiss Feeding Recommendation for lactating sows ${ }^{(17)}$. The usually included animal fat source (blend of tallow and pig fat) was entirely replaced by either CLA-rich alpine butter (BU; experimental diet) or margarine (MA; control diet) (Table 1). The ingredient calculation was done for production units of $500 \mathrm{~kg}$, which resulted in $61 \mathrm{~g}$ alpine butter or margarine per $\mathrm{kg}$ feed. The alpine butter, which contained $859 \mathrm{~g}$ fat $/ \mathrm{kg}$, originated from the Alp Mutten (2100 m altitude; Graubünden, Switzerland), was produced in summer 2004 and stored until use at $-20^{\circ} \mathrm{C}$. The fat content of the margarine (Goldina, Florin AG, Switzerland) was $800 \mathrm{~g} / \mathrm{kg}$. The fat content and fatty acid composition of both diets are shown in Table 2 .

The study was designed as a cross-over experiment and carried out with seventeen multiparous sows (Swiss Large White) at the ALP Swine facility in Posieux (Switzerland) between

Table 1. Composition of lactation diets with alpine butter (BU) and margarine (MA) $(\mathrm{g} / \mathrm{kg})^{*}$

\begin{tabular}{lrr}
\hline & \multicolumn{2}{c}{ Treatment } \\
\cline { 2 - 3 } & BU & MA \\
\hline Wheat & 282 & 282 \\
Maize & 226 & 226 \\
Dry sugarbeet pulp & 100 & 100 \\
Soyabean meal & 257 & 257 \\
Rapeseed meal & 50 & 50 \\
NaCl & 4 & 4 \\
Dicalcium phosphate & 5 & 5 \\
Calcium carbonate & 7 & 7 \\
Vitamin-mineral premix $†$ & 4 & 4 \\
Pellan & 4 & 4 \\
Alpine butter & 61 & 0 \\
Margarine & 0 & 61 \\
\hline
\end{tabular}

* Lactation diet was formulated to contain $13.5 \mathrm{MJ}$ digestible energy and $12 \mathrm{~g}$ crude protein per MJ digestible energy.

† Supplied the following nutrients (per kg diet): $1.2 \mathrm{mg}$ all-trans retinol, $0.006 \mathrm{mg}$ cholecalciferol, $9.9 \mathrm{mg}$ vitamin $\mathrm{E}, 2.8 \mathrm{mg}$ riboflavin, $1.3 \mathrm{mg}$ vitamin $\mathrm{B}_{6}, 0.015 \mathrm{mg}$ vitamin $\mathrm{B}_{12}, 0.2 \mathrm{mg}$ vitamin $\mathrm{K}_{3}, 102 \mathrm{mg}$ pantothenic acid, $10 \mathrm{mg}$ niacin, $0.48 \mathrm{mg}$ folic acid, $84 \mathrm{mg} \mathrm{Fe}$ as iron sulfate, $0.56 \mathrm{mg} \mathrm{I}$ as $\mathrm{Ca}(\mathrm{IO})_{3}, 0.2 \mathrm{mg} \mathrm{Se}$ as $\mathrm{Na}_{2} \mathrm{Se}, 9.2 \mathrm{mg} \mathrm{Cu}$ as $\mathrm{CuSO}_{4}, 81 \mathrm{mg} \mathrm{Zn}$ as $\mathrm{ZnO}_{2}, 2.5 \mathrm{mg} \mathrm{Mn}$ as $\mathrm{MnO}_{2}, 196 \mathrm{~g}$ choline and $0.99 \mathrm{mg}$ biotin.
January and May 2005. At the beginning of the adaptation period, which started 5 to $10 \mathrm{~d}$ before farrowing and lasted until day 5 after farrowing, the sows were blocked by body weight (seven blocks with two sows and one block with three sows per body-weight block) and randomly assigned within each block to two treatment groups. Before farrowing, all sows were offered $2 \mathrm{~kg}$ of the MA diet and within the $5 \mathrm{~d}$ after farrowing the daily allowance of the MA diet was gradually increased from 2 to $5 \cdot 2 \mathrm{~kg}$ per sow. From day 5 until day 15 and from day 16 until day 25 , nine sows were offered $5 \cdot 2 \mathrm{~kg}$ of BU and MA diet (treatment group A: BU-MA). Eight sows in treatment group $\mathrm{B}(\mathrm{MA}-\mathrm{BU})$ were offered

Table 2. Total lipid content (per $100 \mathrm{~g}$ dry matter) and fatty acid concentrations (per $100 \mathrm{~g}$ fat) of alpine butter (BU) and margarine (MA) lactation diets

\begin{tabular}{|c|c|c|}
\hline & \multicolumn{2}{|c|}{ Treatment } \\
\hline & $\mathrm{BU}$ & MA \\
\hline Total lipids (g per 100 g DM) & $8 \cdot 86$ & 8.55 \\
\hline \multicolumn{3}{|c|}{ Fatty acid concentrations (per $100 \mathrm{~g}$ fat) } \\
\hline $14: 0(\mathrm{~g})$ & $4 \cdot 60$ & $3 \cdot 17$ \\
\hline $15: 0(\mathrm{~g})$ & 0.69 & 0.02 \\
\hline $16: 0(\mathrm{~g})$ & $16 \cdot 16$ & $18 \cdot 88$ \\
\hline $17: 0(\mathrm{~g})$ & 0.46 & 0.05 \\
\hline $18: 0(\mathrm{~g})$ & $7 \cdot 32$ & $3 \cdot 71$ \\
\hline $18: 1$ t9 $(\mathrm{g})$ & 0.17 & 0.03 \\
\hline $18: 1 c 9(\mathrm{~g})$ & $19 \cdot 43$ & $20 \cdot 88$ \\
\hline $18: 1 t 10 / 11(\mathrm{~g})$ & 2.53 & $0 \cdot 10$ \\
\hline $18: 2 c 9, c 12(\mathrm{~g})$ & $15 \cdot 78$ & 21.46 \\
\hline \multicolumn{3}{|l|}{ CLA isomers } \\
\hline $18: 2 t 12, t 14(\mathrm{mg})$ & $12 \cdot 53$ & 0.99 \\
\hline $18: 2 t 11, t 13(\mathrm{mg})$ & $22 \cdot 75$ & 0.39 \\
\hline $18: 2 t 10, t 12(\mathrm{mg})$ & $2 \cdot 04$ & $4 \cdot 16$ \\
\hline $18: 2 t 9, t 11(\mathrm{mg})$ & $41 \cdot 87$ & $6 \cdot 76$ \\
\hline $18: 2 t 8, t 10(\mathrm{mg})$ & $4 \cdot 24$ & 4.48 \\
\hline $18: 2 t 7, t 9(\mathrm{mg})$ & 5.01 & 1.96 \\
\hline $18: 2 t 6, t 8(\mathrm{mg})$ & $2 \cdot 17$ & 0.92 \\
\hline $18: 2 \mathrm{ct} / \mathrm{tc} 12,14(\mathrm{mg})$ & 0.05 & 0.66 \\
\hline $18: 2 t 11, c 13(\mathrm{mg})$ & $75 \cdot 65$ & 0.57 \\
\hline $18: 2 c 11, t 13(\mathrm{mg})$ & $2 \cdot 85$ & 0.91 \\
\hline $18: 2 t 10, c 12(\mathrm{mg})$ & 1.71 & $4 \cdot 18$ \\
\hline $18: 2 c 9, t 11(\mathrm{mg})$ & $1003 \cdot 95$ & $11 \cdot 65$ \\
\hline $18: 2 t 8, c 10(\mathrm{mg})$ & 13.00 & 2.95 \\
\hline $18: 2 t 7, c 9(\mathrm{mg})$ & $22 \cdot 60$ & 0.91 \\
\hline$\sum \mathrm{CLA}(\mathrm{mg})$ & $1210 \cdot 42$ & 41.49 \\
\hline $18: 3 c 9, c 12, c 15(\mathrm{~g})$ & $2 \cdot 16$ & 1.85 \\
\hline $20: 3 n-6(g)$ & 0.02 & 0.05 \\
\hline $20: 4 n-6(g)$ & 0.07 & 0.02 \\
\hline $\operatorname{SFA}(g)^{*}$ & $36 \cdot 33$ & 35.92 \\
\hline MUFA $(g) \dagger$ & $26 \cdot 83$ & 24.49 \\
\hline PUFA (g) $\ddagger$ & $21 \cdot 80$ & $24 \cdot 73$ \\
\hline$\sum 18: 1 t(\mathrm{~g}) \S$ & 3.43 & 0.21 \\
\hline$\sum 18: 2(\mathrm{~g})$ & $19 \cdot 35$ & $22 \cdot 67$ \\
\hline$t$ FA without CLA (g)\| & 4.54 & 0.52 \\
\hline$t$ FA with CLA $(\mathrm{g}) \emptyset$ & $5 \cdot 65$ & 0.55 \\
\hline$\sum n-3(g)$ & $4 \cdot 17$ & 2.89 \\
\hline$\sum n-6(\mathrm{~g})$ & $16 \cdot 95$ & $22 \cdot 12$ \\
\hline$n-6: n-3$ & 4.06 & $7 \cdot 65$ \\
\hline
\end{tabular}

$t$, trans; $c$, cis; CLA, conjugated linoleic acid; FA, fatty acids.

${ }^{*} \mathrm{C} 4$ to $\mathrm{C} 10, \mathrm{C} 12, \mathrm{C} 12$ iso, $\mathrm{C} 12$ aiso, $\mathrm{C} 13$ iso, C14, C14 iso, C14 aiso, C15, C15 iso, C16, C16 iso, C16 aiso, C17, C17 iso, C17 aiso, C18, C19, C20 and C22.

†C10:1, C14:1 ct, C16:1 ct, C17:1 ct, C18:1 t4 to C18:1 c14,t16, C20:1 t $\mathrm{C} 20: 1$ c5 to $\mathrm{C} 20: 1 c 11$.

$\ddagger \mathrm{C} 18: 2 \mathrm{tt}$ non-methylene interrupted diene to $\mathrm{C} 18: 2 c 9, c 15, \mathrm{C} 18: 3 c 6, c 9, c 12$,

$\mathrm{C} 18: 3 c 9, c 12, c 15$ to $\mathrm{C} 20: 2 c c, \mathrm{C} 20: 3$ to $\mathrm{C} 22: 6$.

$\S \mathrm{C} 18: 1$ t4 to $\mathrm{C} 18: 1 t 13-14+c 6-8$.

$\| \mathrm{C} 14: 1 t, \mathrm{C} 16: 1 t, \mathrm{C} 17: 1 t, \mathrm{C} 20: 1 t, \mathrm{C} 18: 1 t+\mathrm{C} 18: 2 t$ (without CLA $t$ ).

ๆ $\mathrm{C} 14: 1 t, \mathrm{C} 16: 1 t, \mathrm{C} 17: 1 t, \mathrm{C} 20: 1 t, \mathrm{C} 18: 1 t+\mathrm{C} 18: 2 t+\mathrm{CLA} t$. 
the MA and BU diet from day 5 to day 15 and from day 16 to day 25 , respectively. Based on literature data, it was expected that alterations in the milk lipid composition due to the dietary treatment would occur quickly ${ }^{(6,8,15)}$. Therefore, a washout period between the two dietary treatments was omitted in favour of a waiting period before collecting the first milk samples $(5 \mathrm{~d})$. In the adaptation and experimental phase the sows were individually fed twice per $\mathrm{d}$ and had free access to water. In order to have the same daily feed intake, litter size was adjusted to eight piglets on the day of farrowing. Each sow ingested daily $5.4 \mathrm{~g}$ CLA with the BU diet compared with an intake of only 0.2 g CLA with the MA diet. All procedures involving animals were approved by the Swiss Federal Committee for Animal Care and Use.

\section{Measurements and sampling}

The body weight of the piglets was recorded at birth and at days 5,15 and 25 of age between 07.00 and 09.00 hours. The pigs did not have access to feeds other than the milk. Milk samples ( $50 \mathrm{ml}$ per sow and milking) were collected by milking several udders on days $5,10,15,20$ and 25 from all sows, on day 7 from sows in treatment group $\mathrm{A}$, and on day 17 from sows in treatment group B at 09.00 hours. The piglets were separated from the sows $2 \mathrm{~h}$ before milking. In order to facilitate milking, $3 \mathrm{ml}$ oxytocin (Oxytocin-20; Graeub, Bern, Switzerland) was injected intramuscularly before milking. The milk samples were frozen immediately and stored at $-20^{\circ} \mathrm{C}$ until analysis.

\section{Sample analysis}

Milk fat was obtained gravimetrically using the Röse Gottlieb $\operatorname{method}^{(18)}$. The milk fat was dissolved in hexane, and the acylglycerols were transesterified to the corresponding fatty acid methyl esters using a solution of potassium hydroxide in methanol ( $2 \mathrm{~mol} / \mathrm{l})$ according to ISO standard 15885 . Fatty acid composition was determined using a gas chromatograph (Agilent 6890) equipped with an on-column injector and flame ionisation detector ${ }^{(19)}$. Nearly seventy fatty acids were separated on a capillary column $(100 \mathrm{~m} \times 0.25 \mathrm{~mm} \times 0.20 \mu \mathrm{m}$, $\mathrm{CP}-$ Sil 88) and quantified in absolute values (g fatty acids/ $100 \mathrm{~g}$ fat) using nonanoic acid as internal standard. CLA isomers were analysed by silver-ion $\left(\mathrm{Ag}^{+}\right)$HPLC according to Rickert et al. ${ }^{(20)}$, modified by Kraft et al. ${ }^{(21)}$. The analysis was performed on an Agilent LC series 1100 equipped with a photodiode array detector $(234 \mathrm{~nm})$ using three ChromSpher Lipids columns in series. The solvent consisted of UV-grade hexane with $0.1 \%$ acetonitrile and $0.5 \%$ ethyl ether (flow rate $1 \mathrm{ml} / \mathrm{min}$ ) prepared fresh daily. Injection volumes were $10 \mu \mathrm{l}$, representing $<250 \mu \mathrm{g}$ lipid. The identification of CLA isomers was based on co-injection with commercial reference material and synthesised CLA. The results were expressed as absolute values in $\mathrm{mg}$ per $100 \mathrm{~g}$ fat. Fourteen different CLA isomers were separated by this HPLC method.

\section{Statistical analysis}

Statistical analysis was performed using Systat ${ }^{\circledR}$ for Windows version 11 (Richmond, CA, USA) and Microsoft Excel 2000.
The fatty acid concentrations are expressed as means and pooled standard errors of a difference between means. The two measurements for milk fatty acid concentrations within the same dietary phase (study days $10+15$ and $20+25$, respectively) were compared using paired $t$ tests. All comparisons were not statistically significant $(P>0 \cdot 05)$. Subsequently, the two measurements within a dietary phase were averaged for further statistical analysis. The unpaired two-tailed $t$ test for cross-over design was used to assess differences in milk fatty acid concentrations regarding dietary treatment, and dietary order. Differences between means were considered statistically significant at the $P<0.05$ level. 'Dietary treatment' refers to the impact of the two fat sources (BU $v$. MA) of the pooled data of both groups; 'dietary order' reflects the effect of the order of the treatment.

\section{Results}

The fat content of both diets was similar with $8.86 v .8 .55 \mathrm{~g} /$ $100 \mathrm{~g}$ DM and both diets showed a similar SFA concentration. Higher levels of vaccenic acid (trans-11-18:1; VA) in the alpine butter led to a slightly higher MUFA concentration in the BU diet. The PUFA concentration was somewhat higher in the MA diet but not as much as would have been expected in regard to the more pronounced linoleic acid (cis-9,cis-12$18: 2$ ) content of the MA diet. The reason for this lies in the higher concentration of $n-3$ fatty acids in the BU compared with the MA diet, which is reflected in the $n-6: n-3$ ratios of 4.06 and 7.65 for the BU and MA diets, respectively. Total CLA concentration as well as ten of the fourteen analysed CLA isomers was higher in the BU diet. Exceptions were trans-10,trans-12-, trans-8,trans-10-, trans-10,cis-12-, and cis-12,trans-14/trans-12,cis-14-18:2.

Compared with the MA diet, feeding the BU diet did not alter the fat content of the sow milk (Table 3). The fatty acid profile of the sow milk fat generally reflected the fatty acid profile of the diet. The concentration of linoleic acid in the milk fat increased $(P=0.008)$ during the MA feeding. However, the concentration of myristic (14:0), palmitic (16:0), stearic $(18: 0)$, oleic (cis-9-18:1), and $\alpha$-linolenic (cis-9,cis-12,cis-15-18:3) fatty acids as well as the total amount of SFA, MUFA, and PUFA were not influenced by the diets $(P>0 \cdot 05)$. An increased trans-18:1 concentration in the milk fat during the BU feeding $(P<0.001)$ was noted.

As expected, feeding the BU diet resulted in a significantly higher $(P<0.001)$ total CLA concentration in the milk fat (Table 3). The transfer of CLA from diet into milk occurred rapidly. Within $2 \mathrm{~d}$ after the change from the MA to the $\mathrm{BU}$ diet CLA concentrations in milk were elevated (data not shown). Fourteen individual CLA isomers were separated by HPLC analysis. All CLA isomers determined in the feed were detected in the sow milk fat. Eleven of the fourteen measured CLA isomers increased $(P \leq 0.004)$ during the BU feeding (Table 3). Exceptions were trans-10,trans-12-, trans10,cis-12- and trans-8,trans-10-18:2, which is not surprising since the concentration of these isomers was equal or higher in the MA compared with the BU diet. Interestingly, the concentration of cis-12,trans-14/trans-12,cis-14-18:2 in milk was significantly $(P<0 \cdot 001)$ increased during the BU diet although the concentration was higher in MA than in BU. The most abundant isomers found in the sow milk after 
Table 3. Total lipid content (per $100 \mathrm{~g}$ milk) and fatty acid concentrations of sow milk (per $100 \mathrm{~g}$ milk fat) during alpine butter (BU) and margarine (MA) treatment

(Mean values and pooled standard errors of difference)

\begin{tabular}{|c|c|c|c|c|c|c|c|}
\hline & \multicolumn{2}{|c|}{ Group A $(n 9)$} & \multicolumn{2}{|c|}{ Group B ( $n 8)$} & \multirow[b]{2}{*}{ SED } & \multicolumn{2}{|c|}{$P$} \\
\hline & BU & MA & MA & BU & & Dietary treatment & Dietary order \\
\hline Total lipid (g/100 g milk) & 6.94 & $7 \cdot 21$ & $8 \cdot 19$ & $7 \cdot 93$ & $4 \cdot 60$ & 0.33 & 0.79 \\
\hline \multicolumn{8}{|c|}{ Fatty acid concentrations (per $100 \mathrm{~g}$ milk fat) } \\
\hline $14: 0(\mathrm{~g})$ & 3.78 & 3.45 & $3 \cdot 78$ & $3 \cdot 85$ & $0 \cdot 15$ & 0.02 & $0 \cdot 10$ \\
\hline $15: 0(\mathrm{~g})$ & 0.29 & 0.14 & 0.15 & 0.30 & 0.03 & $<0.01$ & 0.91 \\
\hline $16: 0(\mathrm{~g})$ & $27 \cdot 10$ & $27 \cdot 92$ & 27.55 & $26 \cdot 61$ & 1.05 & $0 \cdot 11$ & 0.91 \\
\hline $17: 0(\mathrm{~g})$ & 0.43 & 0.27 & 0.29 & 0.38 & 0.03 & $<0.01$ & 0.09 \\
\hline $18: 0(\mathrm{~g})$ & 4.42 & $4 \cdot 20$ & $3 \cdot 82$ & 3.92 & 0.23 & 0.18 & 0.62 \\
\hline $18: 1$ t9 (g) & 0.17 & $0 \cdot 10$ & 0.12 & 0.19 & 0.01 & $<0.01$ & 0.44 \\
\hline $18: 1 c 9(\mathrm{~g})$ & $24 \cdot 51$ & $25 \cdot 51$ & 24.92 & $25 \cdot 14$ & $1 \cdot 21$ & 0.53 & 0.33 \\
\hline $18: 1 t 10 / 11(\mathrm{~g})$ & 0.60 & 0.33 & 0.22 & 0.60 & 0.09 & $<0.01$ & 0.25 \\
\hline $18: 2 c 9, c 12(\mathrm{~g})$ & $10 \cdot 62$ & $13 \cdot 45$ & $12 \cdot 73$ & $12 \cdot 27$ & 1.08 & $<0.01$ & 0.05 \\
\hline \multicolumn{8}{|l|}{ CLA isomers } \\
\hline $18: 2 t 12, t 14(\mathrm{mg})$ & $1 \cdot 78$ & 0.44 & 0.35 & $2 \cdot 00$ & 0.45 & $<0.01$ & 0.51 \\
\hline $18: 2 t 11, t 13(\mathrm{mg})$ & $3 \cdot 37$ & $1 \cdot 30$ & $0 \cdot 73$ & $3 \cdot 19$ & 0.65 & $<0.01$ & 0.55 \\
\hline $18: 2 t 10, t 12(\mathrm{mg})$ & $1 \cdot 22$ & 1.84 & $1 \cdot 21$ & $1 \cdot 21$ & 0.31 & 0.07 & 0.07 \\
\hline $18: 2 t 9, t 11(\mathrm{mg})$ & 12.91 & $6 \cdot 98$ & $5 \cdot 44$ & 14.61 & 1.96 & $<0.01$ & 0.12 \\
\hline $18: 2$ t8,t10 (mg) & $1 \cdot 26$ & $2 \cdot 38$ & $2 \cdot 03$ & 1.59 & 0.36 & $<0.01$ & 0.07 \\
\hline $18: 2 t 7,19(\mathrm{mg})$ & $3 \cdot 13$ & $1 \cdot 80$ & $2 \cdot 12$ & 3.50 & 0.65 & $<0.01$ & 0.94 \\
\hline $18: 2$ t6,t8 (mg) & 0.34 & 0.18 & $0 \cdot 24$ & 0.41 & 0.08 & $<0.01$ & 0.99 \\
\hline $18: 2 \mathrm{ct} / \mathrm{tc} 12,14(\mathrm{mg})$ & 0.42 & 0.25 & 0.26 & 0.49 & 0.12 & $<0.01$ & 0.63 \\
\hline $18: 2 t 11, c 13(\mathrm{mg})$ & $12 \cdot 91$ & 0.84 & 0.72 & 14.56 & 2.59 & $<0.01$ & 0.50 \\
\hline $18: 2 c 11, t 13(\mathrm{mg})$ & $2 \cdot 30$ & 0.98 & 0.81 & 2.54 & 0.28 & $<0.01$ & 0.16 \\
\hline $18: 2$ t10,c12 (mg) & $5 \cdot 27$ & $7 \cdot 42$ & 3.73 & 4.45 & 1.65 & 0.40 & $0 \cdot 10$ \\
\hline $18: 2 c 9, t 11(\mathrm{mg})$ & $610 \cdot 40$ & $88 \cdot 25$ & 65.92 & $725 \cdot 68$ & $122 \cdot 19$ & $<0.01$ & 0.28 \\
\hline $18: 2$ t8,c10 (mg) & $13 \cdot 31$ & 3.35 & 2.47 & $15 \cdot 11$ & 2.56 & $<0.01$ & 0.31 \\
\hline $18: 2 t 7, c 9(\mathrm{mg})$ & 14.65 & 6.07 & 5.58 & $17 \cdot 76$ & $2 \cdot 80$ & $<0.01$ & 0.22 \\
\hline$\sum \mathrm{CLA}(\mathrm{mg})$ & $683 \cdot 27$ & $122 \cdot 07$ & 91.59 & $808 \cdot 65$ & $132 \cdot 84$ & $<0.01$ & 0.26 \\
\hline $18: 3 c 9, c 12, c 15(\mathrm{~g})$ & 0.89 & 0.89 & 0.82 & 1.02 & 0.12 & 0.11 & 0.12 \\
\hline $20: 3 n-6(g)$ & 0.07 & 0.08 & 0.08 & 0.09 & 0.01 & 0.65 & 0.15 \\
\hline $20: 4 n-6(g)$ & 0.36 & 0.34 & 0.42 & 0.39 & 0.05 & 0.84 & 0.40 \\
\hline $\operatorname{SFA}(g)^{*}$ & 38.08 & $38 \cdot 23$ & 37.97 & $37 \cdot 19$ & $1 \cdot 17$ & 0.44 & 0.60 \\
\hline MUFA $(\mathrm{g}) \dagger$ & 35.95 & $36 \cdot 21$ & 36.55 & 37.05 & 1.01 & 0.82 & 0.46 \\
\hline PUFA (g) $\ddagger$ & $14 \cdot 17$ & $16 \cdot 14$ & $15 \cdot 08$ & $16 \cdot 16$ & 1.37 & 0.52 & 0.04 \\
\hline$\sum 18: 1 t(\mathrm{~g}) \S$ & 0.97 & 0.55 & 0.42 & 0.99 & 0.11 & $<0.01$ & 0.21 \\
\hline$\sum 18: 2(\mathrm{~g})$ & $12 \cdot 20$ & $13 \cdot 98$ & $13 \cdot 43$ & 14.01 & 1.23 & 0.34 & 0.07 \\
\hline$t$ FA with CLA $(\mathrm{g}) \|$ & $2 \cdot 19$ & 0.93 & 0.75 & $2 \cdot 34$ & 0.27 & $<0.01$ & 0.24 \\
\hline$n-6: n-3$ & $7 \cdot 00$ & $9 \cdot 36$ & $9 \cdot 33$ & $7 \cdot 10$ & 0.63 & $<0.01$ & 0.85 \\
\hline
\end{tabular}

$t$, trans; $c$, cis; CLA, conjugated linoleic acid; FA, fatty acids.

${ }^{*} \mathrm{C} 4$ to $\mathrm{C} 10, \mathrm{C} 12, \mathrm{C} 12$ iso, $\mathrm{C} 12$ aiso, $\mathrm{C} 13$ iso, $\mathrm{C} 14, \mathrm{C} 14$ iso, $\mathrm{C} 14$ aiso, $\mathrm{C} 15, \mathrm{C} 15$ iso, $\mathrm{C} 16, \mathrm{C} 16$ iso, $\mathrm{C} 16$ aiso, $\mathrm{C} 17, \mathrm{C} 17$ iso, $\mathrm{C} 17$ aiso, $\mathrm{C} 18$, $\mathrm{C} 19, \mathrm{C} 20$ and $\mathrm{C} 22$.

+C10:1, C14:1 ct, C16:1 ct, C17:1 ct C18:1 t4 to C18:1 c14,t16, C20:1 t C20:1 c5 to C20:1 c11.

$\ddagger C 18: 2 t t$ non-methylene interrupted diene to $C 18: 2 c 9, c 15, C 18: 3 c 6, c 9, c 12, C 18: 3 c 9, c 12, c 15$ to $C 20: 2 c c, C 20: 3$ to $C 22: 6$.

$\S \mathrm{C} 18: 1$ t4 to $\mathrm{C} 18: 1 \mathrm{t} 13-14+c 6-8$.

$\| \mathrm{C} 14: 1 t, \mathrm{C} 16: 1 t, \mathrm{C} 17: 1 t, \mathrm{C} 20: 1 t, \mathrm{C} 18: 1 t+\mathrm{C} 18: 2 t+\mathrm{CLA} t$

BU feeding were cis-9,trans-11-18:2, followed by trans-7, cis-9-18:2, trans-8,cis-10-, trans-9,trans-11-, and trans-11, cis-13-18:2. There was no $(P>0 \cdot 05)$ dietary order effect for the concentration of individual CLA isomers.

The growth performance of the progeny was not influenced by the dietary treatments (Fig. 1). During the BU diet of the sows the body weight of the litter increased 2.48 (SD 0.78) $\mathrm{kg}$; during the MA diet $2.52(\mathrm{SD} 0.81) \mathrm{kg}$. The difference was not statistically significant $(P=0 \cdot 82)$.

\section{Discussion}

The present study demonstrates that a $10 \mathrm{~d}$ supplementation with alpine butter, a naturally CLA-rich product, affects the CLA isomer content of sow milk without influencing significantly the total fat content and the overall composition of SFA, MUFA and PUFA.

No influence of trans-10,cis-12-18:2 on total milk fat as previously shown by Masters et al. ${ }^{(8)}$ was noticed, probably because of the very low concentration of this isomer in both diets.

In general, the fatty acid profile of the sow milk reflected that of the diet. However, the small differences in the concentration of total MUFA and PUFA in the two diets did not lead to significant differences in the sow milk fat. The higher concentration of linoleic acid in MA may be the reason for the increased linoleic acid concentration in the milk fat during MA feeding but the effect was not powerful enough to have a statistically significant impact on the total PUFA concentration. The difference in the linoleic acid concentration was more important (dietary order effect; $P=0 \cdot 04$ ) in treatment 


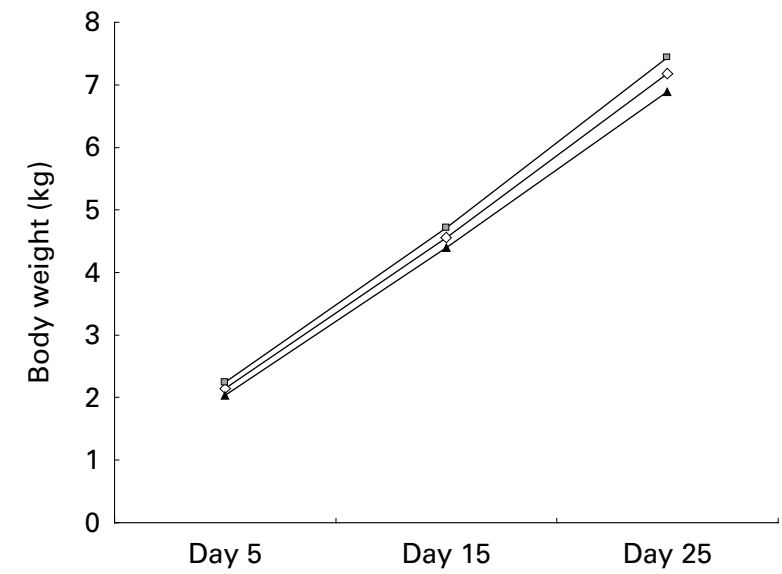

Fig. 1. Mean body weight $(\mathrm{kg})$ of litter $(n$ 135) during the study period for all animals $\left(-\diamond_{-}\right)$, group A $(-\square-)$ and group B $(-\Delta-)$. Values are means.

group A (BU-MA) than in treatment group B (MA-BU) and might be caused by the longer foregoing phase with MA feeding of the latter.

There was no significant dietary order effect for the concentration of individual CLA isomers. Therefore, it can be assumed that the waiting period of 5 and $10 \mathrm{~d}$, respectively, before milk was sampled was long enough to eliminate any carry-over effect.

Dietary VA is converted to cis-9,trans-11-18:2 in human and animal tissues ${ }^{(22-25)}$. In humans the conversion rate is estimated to be about $19 \%^{(23)}$. Because alpine butter naturally contains VA, it has to be assumed that the cis-9,trans-11-18:2 found in the sow milk partially derived from VA. To estimate the transfer of VA, we calculated a discrimination factor (i.e. the relationship of the percentage trans-18:1 isomer of the total MUFA content in the milk fat as compared with that of the diet) as proposed by Pettersen \& Opstvedt ${ }^{(26)}$. The calculated discrimination factor for trans-10/trans-11-18:1 was $0 \cdot 17$, indicating that only a small proportion of VA was actually transferred into the milk fat. Calculating the discrimination factor for cis-9,trans-11-18:2 in the same way (in relation to the PUFA content of diet and milk) yielded a factor of 0.96. Since Bee ${ }^{(4)}$ documented in his publication a discrimination factor of only 0.69 , this suggests that some of the cis-9,trans-11-18:2 in the present study derives from VA.

Compared with the MA dietary treatment, the total CLA content in sow milk was significantly increased during the BU dietary treatment. This is in agreement with findings from human studies, in which a CLA-rich diet led to an increased CLA concentration in mothers' milk $^{(6,9,15,27)}$. The basal CLA concentration in the mothers' milk determined in the study of Bertschi et al. ${ }^{(15)}$ was higher than that observed in the mature milk of the sows, which is probably the result of the normally higher CLA intake by humans than by sows. The lactation diet of sows does not usually contain any natural sources of CLA. However, after supplying the diet with alpine butter the increase in the overall CLA concentration was higher in the milk of sows (560 and $883 \%$ of basal values for group $\mathrm{A}$ and $\mathrm{B}$, respectively) than in the milk of the mothers (128 and $169 \%$ for the two groups, respectively) in the study of Bertschi et al. ${ }^{(15)}$, so that total CLA concentration in milk fat after the BU diet was twice as high in sows $(683.3$ and $808.7 \mathrm{mg} / 100 \mathrm{~g}$ fat in group $\mathrm{A}$ and $\mathrm{B}$, respectively) compared with humans $\left(397.9\right.$ and $436.6 \mathrm{mg} / 100 \mathrm{~g}$ fat $\left.{ }^{(15)}\right)$. These findings were expected because in the sow diet the sole dietary fat source was alpine butter whereas in the human study the alpine butter was one part of the total dietary fat. Considering that sow milk contains about twice as much milk fat than human milk (during alpine butter dietary treatment: $7.3 \mathrm{~g}$ / $100 \mathrm{ml}$ in sow milk and $3.4 \mathrm{~g} / 100 \mathrm{ml}$ in human milk), this results in a four times higher amount of CLA per ml milk in sows than in human mothers. This seems to be in agreement with the fact that the sows ingested with the BU diet daily about four times the amount of CLA than the women (20.8 v. $5.9 \mathrm{mg} / \mathrm{kg}$ body weight). The results suggest that there is potential to substantially increase the CLA content of human milk; however, it is still unclear to what extent. Fogerty et al. ${ }^{(28)}$ reported a high CLA concentration in the milk of Hare Krishna mothers $(1120 \mathrm{mg} / 100 \mathrm{~g}$ fat $)$ and attributed it to a high consumption of butter, ghee and cheese. However, Precht \& Molkentin ${ }^{(29)}$ have analysed milk samples of forty German women and the result (400 (SD 90) mg CLA/100g fat) documents that usually CLA concentration in human milk is lower.

In previous studies, only a few CLA isomers were determined in human ${ }^{(6,9)}$ and sow milk ${ }^{(4)}$. Most analyses concentrate on the predominant cis-9,trans-11-18:2. Bertschi et al. ${ }^{(15)}$ were the first to describe the levels of fourteen individual CLA isomers in human milk. In the present study, the behaviour of most individual CLA isomers was homogeneous insofar as concentrations increased in the sow milk during the BU dietary treatment. Exceptions were, as already mentioned, trans10,trans-12-, trans-10,cis-12- and trans-8,trans-10-18:2, which is ascribable to the fact that the concentrations of these isomers were similar or even higher in the MA compared with the BU diet. Calculating the discrimination factors, in relation to total PUFA concentration as described above, may provide an indication of the transfer efficiency of the individual isomers. This was done for all measured CLA isomers with a concentration $>10 \mathrm{mg} / 100 \mathrm{~g}$ fat in the BU feed. The discrimination factors were similarly low for trans12,trans-14- (0.22), trans-11,trans $13-(0.21)$ and trans-11, cis-13-18:2 (0-26). By contrast, cis-9,trans-11- (0.96), trans7,cis-9- (1.03), and trans-8,cis-10-18:2 (1.57) were incorporated at a very high level, whereas trans-9,trans-11-8:2 (0.47) ranged in the middle. This suggests that individual CLA isomers are not absorbed proportionally from the diet but may also indicate differences in metabolism or variations in tissue deposition of individual CLA isomers. Since the total volume of sow milk could not be collected, a definitive conclusion regarding the quantitative transfer of individual CLA isomers and fatty acids cannot be drawn.

Milk fat usually contains trans-11,cis-13-18:2 and trans7, cis-9-18:2 in a ratio of about $0 \cdot 3$. Alpine milk diverges from this with a ratio of about 3.0 which can be used to confirm the alpine origin ${ }^{(21)}$. This is above all due to an increased trans-11,cis-13-18:2 concentration of highland compared with lowland milk. The trans-11,cis-13 to trans-7,cis-9-18:2 ratio in the BU diet was 3.4. However, in the milk fat of the sows this ratio was only 0.9 during BU feeding. Similarly, Bertschi et al. ${ }^{(15)}$ reported a trans-11, cis-13 to trans-7,cis-9$18: 2$ ratio of 1.1 in human milk fat during alpine butter supplementation. The above-documented discrimination factors 
indicate that the ratio change is basically due to a limited transfer of trans-11,cis-13-18:2 from diet to milk whereas trans-7,cis-9-18:2 goes over approximately $1: 1$. These findings suggest that although trans-11,cis-13-18:2 is increased by highland pasturing of cows, the higher concentration is not utilised by the organisms of sows and humans.

The growth performance of the piglets was not influenced by dietary treatments, which may be due to the short $(10 \mathrm{~d})$ intervention period. Since the main objective of the present study was to investigate the impact of a diet with alpine butter on the fatty acid composition of sow milk, the study was not specifically designed to determine the effect of CLA supply on the growth performance of the progeny. Further studies with longer intervention periods will have to look more specifically into this matter. However, results from Bee ${ }^{(5)}$ suggest that a CLA supplementation of sows during lactation is not sufficient but has to be continued in the post-weaning period to significantly enhance the weight of piglets.

In summary, the findings show that CLA originating from alpine butter positively affects the CLA content of sow milk without provoking a milk fat depression and altering the composition of total SFA, MUFA and PUFA. Furthermore, the data suggest that individual CLA isomers do not go over proportionally from the diet into the milk. However, further studies are necessary to evaluate the quantitative transfer of individual CLA isomers and their physiological effects in the progeny.

\section{Acknowledgements}

The authors would like to thank all their colleagues who were involved in the study for their excellent assistance. All authors participated in the development of the study concept and design; A. S. and G. B. were responsible for the execution of the study; M. C. was responsible for the lipid analysis; A. S. and U. B. were responsible for the statistical analysis; all authors were involved in the data interpretation; A. S. wrote the draft of the manuscript; M. C., G. B., U. B., D. W., P. E. and R. S. reviewed and revised the manuscript. The study was supported by the research budget of Agroscope Liebefeld-Posieux Research Station ALP. None of the authors had any personal or financial conflict of interest.

\section{References}

1. Wahle KWJ, Heys SD \& Rotondo D (2004) Conjugated linoleic acids: are they beneficial or detrimental to health? Prog Lipid Res 43, 553-587.

2. Pariza MW, Park Y \& Cook ME (2001) The biologically active isomers of conjugated linoleic acid. Prog Lipid Res 40, 283-298.

3. Chin SF, Storkson JM, Albright KJ, Cook ME \& Pariza MW (1994) Conjugated linoleic acid is a growth factor for rats as shown by enhanced weight gain improved feed efficiency. J Nutr 124, 2344-2349.

4. Bee G (2000) Dietary conjugated linoleic acids alter adipose tissue and milk lipids of pregnant and lactating sows. $J$ Nutr 130, 2292-2298.

5. Bee G (2000) Dietary conjugated linoleic acid consumption during pregnancy and lactation influences growth and tissue composition in weaned pigs. J Nutr 130, 2981-2989.

6. Park Y, McGuire MK, Behr R, McGuire MA, Evans MA \& Shultz TD (1999) High-fat dairy product consumption increases delta $9 c, 11 t-18: 2$ (rumenic acid) and total lipid concentrations of human milk. Lipids 34, 543-549.

7. Anderson NK, Beerman KA, McGuire MA, Dasgupta N, Griinari JM, Williams J \& McGuire MK (2005) Dietary fat type influences total milk fat content in lean women. J Nutr 135, 416-421.

8. Masters N, McGuire MA, Beerman KA, Dasgupta N \& McGuire MK (2002) Maternal supplementation with CLA decreases milk fat in humans. Lipids 37, 133-138.

9. Ritzenthaler KL, McGuire MK, McGuire MA, Shultz TD, Koepp AE, Luedecke LO, Hanson TW, Dasgupta N \& Chew BP (2005) Consumption of conjugated linoleic acid (CLA) from CLA-enriched cheese does not alter milk fat or immunity in lactating women. $J$ Nutr 135, 422-430.

10. Kelsey JA, Corl BA, Collier RJ \& Bauman DE (2003) The effect of breed, parity, and stage of lactation on conjugated linoleic acid (CLA) in milk fat from dairy cows. J Dairy Sci 86, $2588-2597$.

11. Collomb M, Schmid A, Sieber R, Wechsler D \& Ryhänen E-L (2006) Conjugated linoleic acids in milk fat: variation and physiological effects. Int Dairy J 16, 1347-1361.

12. Kelly ML, Kolver ES, Bauman DE, van Amburgh ME \& Muller LD (1998) Effect of intake of pasture on concentrations of conjugated linoleic acid in milk of lactating cows. J Dairy Sci 81, $1630-1636$.

13. Collomb M, Bütikofer U, Sieber R, Bosset JO \& Jeangros B (2001) Conjugated linoleic acid and trans fatty acid composition of cows' milk fat produced in lowlands and highlands. J Dairy Res 68, 519-523.

14. Collomb M, Bütikofer U, Sieber R, Jeangros B \& Bosset JO (2002) Composition of fatty acids in cow's milk fat produced in the lowlands, mountains and highlands of Switzerland using high-resolution gas chromatography. Int Dairy J 12, 649-659.

15. Bertschi I, Collomb M, Rist L, Eberhard P, Sieber R, Bütikofer U, Wechsler D, Folkers G \& von Mandach U (2005) Maternal dietary alpine butter intake affects human milk: fatty acids and conjugated linoleic acid isomers. Lipids 40, 581-587.

16. Hörr HP (1973) Das Schwein als Versuchstier für die Humanmedizin: eine Literaturstudie (The pig as an experimental animal for human medicine: a literature study). PhD Thesis. Hannover: Tierärztliche Hochschule.

17. Agroscope Liebefeld-Posieux (2004) Fütterungsempfehlungen und Nährwerttabellen für Schweine (Feeding Recommendations and Feeding Value Tables for Pigs), 3rd ed. Zollikofen, Germany: Landwirtschaftliche Lehrmittelzentrale.

18. International Dairy Federation/International Organization for Standardization/Association of Official Agricultural Chemists (1996) Milk - Determination of Fat Content. Standard 001D. Brussels: IDF.

19. Collomb M \& Bühler T (2000) Analyse de la composition en acides gras de la graisse de lait, I. Optimisation et validation d'une méthode générale à haute résolution (Analysis of the fatty acid composition of milk, I. Optimisation and validation of a general high resolution method). Mitt Lebensm Hyg 91, 306-332.

20. Rickert R, Steinhart H, Fritsche J, Sehat N, Yurawecz MP, Mossoba MM, Roach JAG, Eulitz K, Ku Y \& Kramer JKG (1999) Enhanced resolution of conjugated linoleic acid isomers by tandem-column silver-ion high performance liquid chromatography. J High Resolut Chromatogr 22, 144-148.

21. Kraft J, Collomb M, Möckel P, Sieber R \& Jahreis G (2003) Differences in CLA isomer distribution of cow's milk lipids. Lipids 38, 657-664.

22. Gläser KR, Scheeder MRL \& Wenk C (2000) Dietary C18:1 trans fatty acids increase conjugated linoleic acid in adipose tissue of pigs. Eur J Lipid Sci Technol 102, 684-686.

23. Turpeinen AM, Mutanen M, Aro A, Salminen I, Basu S, Palmquist DL \& Griinari JM (2002) Bioconversion of vaccenic acid to conjugated linoleic acid in humans. Am J Clin Nutr 76, 504-510. 
24. Loor JJ, Lin XB \& Herbein JH (2002) Dietary trans-vaccenic acid (trans 11-18:1) increases concentration of cis9, trans11conjugated linoleic acid (rumenic acid) in tissues of lactating mice and suckling pups. Reprod Nutr Dev 42, 85-99.

25. Mosley EE, Shafii B, Moate PJ \& McGuire MA (2006) Cis-9, trans-11 conjugated linoleic acid is synthesized directly from vaccenic acid in lactating dairy cattle. J Nutr 136, $570-575$.

26. Pettersen J \& Opstvedt J (1991) Trans fatty acids. 4. Effects on fatty acid composition of colostrum and milk. Lipids 26, $711-717$.
27. Mosley SA, Shahin AM, Williams J, McGuire MA \& McGuire MK (2007) Supplemental conjugated linoleic acid consumption does not influence milk macronutrient contents in all healthy lactating women. Lipids 42, 723-729.

28. Fogerty AC, Ford GL \& Svoronos D (1988) Octadeca-9,11-dienoic acid in foodstuffs and in the lipids of human blood and breast milk. Nutr Rep Int 38, 937-944.

29. Precht D \& Molkentin J (1999) C18 : 1, C18:2 and C18: 3 trans and $c i s$ fatty acid isomers including conjugated cis $\Delta 9$,trans $\Delta 11$ linoleic acid (CLA) as well as total fat composition of German human milk lipids. Nahrung 43, 233-244. 